\title{
CAPACITAÇÃO DE PROFESSORES PARA A PROMOÇÃO E EDUCAÇÃO EM SAÚDE NA ESCOLA: RELATO DE UMA EXPERIÊNCIA*
}

\section{TEACHER TRAINING FOR HEALTH PROMOTION AND EDUCATION IN SCHOOL: AN EXPERIENCE REPORT}

Iervolino AS, Pelicioni MCF. Capacitação de professores para a promoção e educação em saúde na escola: relato de uma experiência. Rev Bras Cresc Desenv Hum 2005; 15(2):99-110.

\begin{abstract}
Resumo: Este trabalho, desenvolvido por trinta meses em Vargem Grande Paulista-SP, objetivou capacitar professores do Ensino Infantil e Fundamental para desenvolverem o processo de Educação em Saúde, junto a seus alunos. Utilizou-se um questionário com perguntas abertas e fechadas e a técnica de grupo focal, sendo os resultados analisados quali-quantitativamente. Iniciou-se com um diagnóstico situacional, originando os seguintes "temas geradores": Escola Promotora da Saúde, Observação do Escolar, Prevenção de Acidentes, entre outros. Esses possibilitaram a discussão de saúde de forma integral e o estabelecimento da relação desta com o meio ambiente. A segunda etapa se constituiu na avaliação do processo. Como resultados, a capacitação realizada, calcada na idéia de saúde como sinônimo de qualidade de vida, proporcionou aos professores a possibilidade de revisar seus conceitos sobre saúde e educação em saúde, seu papel como agente promotor da saúde e da prevenção de doenças. Verificou-se também que se tornaram capacitados para desenvolver os temas trabalhados de forma transversal.
\end{abstract}

Palavras-chave: Educação em Saúde. Promoção da Saúde. Escola Promotora da Saúde. Educação Continuada.

A partir da I Conferência sobre a Promoção da Saúde de Ottawa, Canadá, em 1986, formulou-se um documento, denominado Carta de Ottawa, no qual a concepção de Promoção da Saúde passou a valorizar o impacto que as condições sócio-econômicas, políticas e culturais exercem sobre a saúde dos indivíduos, bem como reconheceu que a promoção da saúde se dá por meio de atividades intersetoriais e não como responsabilidade exclusiva do setor saúde.

Esse novo paradigma deve reconhecer a saúde como qualidade de vida resultante de condições de vida como a qualidade da nutrição e a quantidade adequada de alimentação, garantia de educação formal de qualidade nos diversos estágios da vida, condições adequadas de trabalho, apoio social para o indivíduo e para a comunidade, e boas condições de habitação e saneamento. Envolve a combinação entre a sociedade civil e os governos para que se obtenham ações que causem impacto positivo nos estilos e condições de vida.

A capacitação para a educação em saú-

Artigo baseado na Dissertação de Mestrado: "Escola Promotora da Saúde: um projeto de qualidade de vida", 2000, Faculdade de Saúde Pública da Universidade de São Paulo.

** Preceptora da Escola de Formação em Saúde da Família Visconde de Sabóia - Sobral -CE e Doutoranda da Faculda de de Saúde Pública da Universidade de São Paulo. e-mail: abrocesi@ usp.br

*** Profa Associada do Departamento de Prática de Saúde Pública da Universidade de São Paulo. 
de de professores, fundamentada na Promoção da Saúde, deve fazer parte da formação acadêmica desses profissionais, estando incluída no currículo. Porém, para a efetivação dessa capacitação é necessário que haja a incorporação de valores e conceitos positivos de saúde. Para tanto, é imprescindível que, após o primeiro contato com a fundamentação teórica sobre Promoção e Educação em Saúde, ocorrida durante a formação acadêmica, o professor esteja inserido em um processo que possibilite sua atualização, compreensão e aperfeiçoamento de conhecimentos sobre o processo de nascer, viver, envelhecer, adoecer e morrer ${ }^{1}$.

A Educação em Saúde, com vistas à Promoção da Saúde, tem por objetivo capacitar os educandos para atuarem como agentes transformadores e partícipes de movimentos que defendam a preservação e a sustentabilidade do meio-ambiente, que lutem por melhores condições de vida e saúde, que tenham maior acesso às informações em saúde, à cultura e ao lazer e pela garantia de que o Estado cumpra seus deveres para com os cidadãos, baseados na Constituição Federal ${ }^{2}$.

A responsabilidade nesse processo contínuo e permanente de se educar não pode ser solitária nem partir apenas de iniciativas individuais. Deve ser fruto de uma política de governo, apoiada, incentivada e facilitada pelas instituições escolares, fundamentada no entendimento de que o conhecimento é resultante de um processo histórico ligado à cultura, um ato que interfere na construção da sociedade, necessário para " $[. .$.$] continuar a viver com intensida-$ de, para poder criar, para poder construir o que ainda não está aî”’3 (p.28).

A educação continuada deve ser um processo dinâmico e participativo, que facilite ao indivíduo o seu desenvolvimento, de modo que esse sinta que está crescendo enquanto pessoa e, portanto, impulsionando sua evolução, modificando o seu entorno e contribuindo para a evolução da sociedade.
A educação continuada em saúde, como uma ferramenta da promoção da saúde, deve ser entendida como uma estratégia para habilitar profissionais para planejar, desenvolver, avaliar e reestruturar os serviços, aos quais pertencem.

Assim sendo, um processo de educação continuada para professores, que visa à promoção da saúde no âmbito escolar deve partir de uma visão integral do ser humano, considerando-o em seu contexto familiar, comunitário e social ${ }^{4}$.

O processo de educação em saúde na escola traz como resultante, para a comunidade envolvida, novos conhecimentos, habilidades e destrezas para o cuidado com a saúde e para a prevenção de doenças e de condutas de riscos; fomenta a análise crítica e reflexiva sobre os valores, condutas, condições sociais e estilos de vida.

O processo deve buscar também desenvolver e fortalecer aquilo que favorece a saúde e o desenvolvimento humano; facilitar a participação da comunidade envolvida no processo para a tomada de decisões; no "empowerment" de condutas positivas na busca de qualidade de vida e contribuir para promover relações socialmente igualitárias para a construção da cidadania e democracia, reforçando o espírito comunitário e a solidariedade ${ }^{1}$.

Há alguns anos o termo empoderamento, do espanhol, tem sido utilizado no Brasil como sinônimo da palavra inglesa "empowerment". Para Martins-Junior ${ }^{5}$, o termo apoderamento manifesta de forma mais fiel o conceito de Promoção da Saúde aqui adotado, uma vez que se trata de um processo de reconhecimento do poder que existe, de trazer o poder mais próximo de si, contrariamente à palavra empoderamento que significa "dar poder a".

A capacitação de professores para ensinar e aprender Promoção e Educação em Saúde deve ser permanente, necessariamente ligada a uma ação dinâmica, ininterrupta e atualizada, não devendo ser vista como uma forma de 
atender às deficiências da graduação. "Esse desenvolvimento contínuo justifica-se por várias razões decorrentes do avanço constante do conhecimento científico e das investigações relacionadas à Educação, à Cultura, e às Artes, entre outros, decorrentes das mudanças e evolução da sociedade em suas estruturas materiais e institucionais, nas formas de organização da convivência e na produção dos modelos econômicos"6 (p. 253).

Assim sendo, o planejamento de programas de educação permanente, para os professores e adultos em geral, não esquecendo que estes já são possuidores de diferentes experiências tanto pessoais como profissionais, requer o desenvolvimento de uma consciência crítica dos participantes.

A educação embasada numa prática reflexiva prepara o educando para a vida e para assumir uma posição ideológica quanto ao papel que o Estado deve assumir frente às questões públicas, dentre elas, as políticas educacionais e a prioridade que este dá a promoção de modos de vida saudáveis das crianças e dos jovens dentro e fora das escolas, incluindo também atividades recreativas saudáveis e seguras ${ }^{1,7}$.

Desenvolver uma consciência crítica se faz cada vez mais urgente; como todo saber é limitado e passível de superação, isso só será possível à medida que os homens respondam aos desafios do mundo, transcendendo os espaços geográficos e modificando a realidade, enfim, na medida em que "escrevam" a história da sociedade pela sua própria atividade criadora $^{8}$.

A Educação em Saúde, como uma poderosa ferramenta da Promoção da Saúde, tem por objetivo capacitar os educandos para atuarem como agentes transformadores e defensores da preservação e da sustentabilidade do meio-ambiente, para lutarem por melhores condições de vida e saúde, para ter maior acesso às informações em saúde, à cultura e ao lazer baseados nos seus direitos determinados e ga- rantidos pela Constituição Federal ${ }^{2}$.

A educação em saúde na escola deve trazer aos alunos um enfoque integral de saúde em todas as etapas de seu desenvolvimento. Trabalhando com a auto-estima das crianças e jovens, com a capacidade de adquirir hábitos de higiene e adotar formas de vida saudáveis, a educação em saúde não se limita a transmitir informações de uma matéria específica, mas deve buscar o desenvolvimento de conhecimentos, hábitos e habilidades que contribuam para a adoção de um modo de vida mais saudável bem como para a capacidade reflexiva perante os acontecimentos da vida ${ }^{1}$.

Baseada nos pressupostos da educação em saúde, a iniciativa da Escola Promotora da Saúde, proposta pela Organização Mundial da Saúde, apresenta como características o incentivo à formação e o favorecimento da atualização do corpo docente, com o objetivo de melhorar a saúde de todos que convivem na escola e em seu entorno; de contribuir para a manutenção, preservação e sustentabilidade do meio ambiente; de prevenir as enfermidades e os riscos de acidentes; de promover a auto-estima;de reduzir gastos, bem como avaliar a eficácia das ações desenvolvidas ${ }^{4}$.

A educação continuada em Vargem Grande Paulista, São Paulo, foi desenvolvida por solicitação da Secretaria Municipal da Educação à Faculdade de Saúde Pública da Universidade de São Paulo, tendo como objetivo capacitar os professores do Ensino Infantil e Fundamental para a Promoção e Educação em Saúde na escola seguindo os fundamentos da Escola Promotora da Saúde.

O processo de educação continuada para a promoção e a educação em saúde na escola foi desenvolvido em cinco escolas-pólos, representativas das cinco Regiões do Município de Vargem Grande Paulista, São Paulo, em duas fases de janeiro de 1998 a julho de 2000, numa parceria da Faculdade de Saúde Pública da USP com as Secretarias Municipais da Saúde e da 
Educação.

Na primeira fase, 20 professores que lecionavam no Ensino Infantil ou Fundamental responderam a um questionário de perguntas abertas e fechadas e, após análise quali-quantitativa dos resultados, houve uma complementação e aprofundamento dos temas por meio da utilização da técnica de grupo focal, permitindo identificar as necessidades e interesses dos professores para a realização do diagnóstico situacional e do desenvolvimento do processo de Educação Continuada.

O grupo focal é uma técnica de pesquisa que utiliza sessões grupais, como um dos fóruns facilitadores da expressão ou das percepções, crenças, valores e atitudes sobre questões específicas ${ }^{9}$.

A $2^{\mathrm{a}}$ fase, de avaliação do impacto das ações, feita por meio da comparação qualitativa dos resultados das duas fases, foi realizada ao final do processo utilizando-se os mesmos instrumentos metodológicos da primeira fase, bem como os mesmos procedimentos para a coleta dos dados.

Para a realização do grupo focal, nesta fase, acrescentaram-se mais duas questões ao roteiro anteriormente utilizado que permitiram discutir com os professores participantes sobre a satisfação de suas expectativas quanto aos temas e a metodologia utilizadas, bem como a sua aplicação na prática cotidiana.

Decidiu-se, então, iniciar a capacitação pelos temas por eles priorizados, que se transformaram em temas geradores, uma vez que possibilitaram a discussão sobre outros assuntos complementares, visando sempre à saúde integral e permitindo que se estabelecessem relações com a área ambiental. Essa opção constituiu-se em um dos elementos responsáveis pelo êxito da proposta de educação continuada, pois o processo de educação para ser mais preciso deve ser estabelecido por meio da análise das reais necessidades da população alvo ${ }^{3}$.
Aos temas escolhidos foram incorporados assuntos identificados pelos técnicos envolvidos neste estudo, como necessários para complementar, ou ampliar as discussões sobre a promoção da saúde e a educação em saúde, sobre a prevenção de doenças e sobre os recursos de saúde disponíveis para o encaminhamento, tratamento e recuperação de danos físicos.

O programa de educação continuada realizou-se por meio do uso de diferentes técnicas como: cursos, seminários, "workshops", discussões em grupo e oficinas de sensibilização, entre outros.

Durante toda a duração do processo, a equipe de técnicos trabalhou em parceria com os professores, acompanhando-os e orientando-os nessa "nova" forma de abordar os temas já contidos no plano de ensino. Assim sendo, as questões de saúde - entendida como sinônimo de qualidade de vida e resultante das condições de vida -, a promoção e a educação em saúde foram abordadas de forma a serem inseridas em classe como temas transversais tendo como base de discussão e reflexão os cinco sentidos: visão, audição, olfato, paladar e tato.

Entre os temas selecionados pelos professores e pelo grupo de trabalho da Faculdade de Saúde Pública da USP para a educação continuada, destacam-se:

$\begin{array}{ll}\checkmark & \text { Escola Promotora da Saúde } \\ \checkmark & \text { Observação do escolar } \\ \checkmark & \text { Saúde Ocular } \\ \checkmark & \text { Tracoma } \\ \checkmark & \text { Saúde Auditiva } \\ \checkmark & \text { Verminose } \\ \checkmark & \text { Prevenção de Doenças Infecciosas e } \\ \text { Vacinação } \\ \checkmark & \text { Prevenção de Acidentes na Escola } \\ \checkmark & \text { Intercorrências Mais Comuns e Primeiros } \\ \text { Socorros na Escola } \\ \checkmark & \text { Alimentação, Subnutrição e Anemia }\end{array}$




\section{Escola Promotora da Saúde}

A educação no âmbito escolar deve objetivar algo mais do que o ensino formal de matérias curriculares (matemática, história, ciências, entre outras). A escola deve servir de fonte para o aprendizado de elementos que substanciem as vivências e as práticas escolares, tendo como base valores positivos. Sua finalidade também é formar cidadãos participantes da sociedade, conscientes de seus direitos e deveres e que reconheçam que a qualidade de vida é fator predominante para a obtenção da saúde. Isso reforça a importância de introduzir a escola como promotora da saúde da infância e da adolescência ${ }^{1}$.

Explicar os conteúdos técnicos não basta; é preciso contribuir para que os professores possam analisar e refletir sobre as bases sociais de suas vidas, qual seja, sobre as suas condições de trabalho, de moradia, as alternativas de lazer no bairro em que moram, os problemas de agravos à saúde presentes em seu meio, na escola e na comunidade. Foi baseada nesses pressupostos que, ao longo de todo o tempo, deu-se o processo de educação continuada incluindo os temas acima descritos.

Entre as características da escola promotora da saúde, podem-se destacar: o planejamento, desenvolvimento e valorização no currículo formal de programas de promoção da saúde, educação em saúde e prevenção de doenças. Esses programas devem incentivar o respeito mútuo, a auto-estima, o conhecimento do corpo pelo aluno e a observação sistematizada do escolar pelos professores; a preservação do patrimônio; o cuidado e a manutenção do meio ambiente dentro e fora da escola; a atenção aos conteúdos dos programas para que sejam desenvolvidos de forma dinâmica e estimulante. Devem permitir também que os alunos adquiram valores, a serem perpetuados para o restante de suas vidas, tais como liberdade, democracia, eqüidade e justiça. Deve possibilitar, igualmente, o incentivo, a formação e a atualização do corpo docente, como forma de revalorizar os profissionais que atuam como agentes fundamentais de promoção da saúde dentro da escola ${ }^{2}$.

\section{Observação do escolar}

Sendo a escola um local privilegiado para a observação da situação de saúde das crianças, os professores podem fazê-la na sala de aula enquanto desenvolvem suas tarefas; durante o recreio; quando estão sós ou em grupos e durante a entrada e saída da escola.

Observar é o ato de prestar atenção, olhar com minúcia e detalhamento. É utilizar todos os órgãos do sentido para descrever algo ou alguém que, com alguma finalidade, planejamos observar ${ }^{10}$. A observação planejada, feita com objetivos definidos (observação sistematizada) pode dar ao professor subsídios para trabalhar os assuntos relativos à saúde.

Durante o processo desenvolvido neste estudo, procurou-se discutir com os professores o método da observação sistematizada que visa, principalmente, detectar os desvios dos padrões esperados para o crescimento e desenvolvimento dos seres humanos, uma vez que as condições de saúde da criança, além de interferir no desenvolvimento e no crescimento, também interferem no rendimento escolar. É preciso ressaltar que antes de levantar questões sobre os desvios de normalidade é necessário reconhecer os conceitos e padrões de normalidade adotados pelos professores; desta forma, os debates devem centrar-se, primeiramente, nos conhecimentos por eles adquiridos previamente.

É na escola que a criança passa grande parte de seu dia-a-dia, muitas vezes o percentual de tempo de estada com o professor supera a convivência diária com os pais que, freqüentemente trabalham fora do ambiente doméstico, ausentando-se por muitas horas. 
O professor preparado para reconhecer os sinais e sintomas das doenças mais freqüentes na idade escolar e para perceber dificuldades no ambiente físico e social da escola estará mais apto a resolver os problemas detectados, encaminhando-os imediatamente e evitando, desta forma, que ocorram distúrbios ou seqüelas que poderão afetar as crianças para o resto de suas vidas.

É importante, também, que se tenha um local apropriado para fazer as anotações dos problemas e dos respectivos encaminhamentos, isto é, uma ficha padronizada segundo as necessidades da escola, conforme sugestão que se encontra em anexo.

Aos serviços de saúde cabe o preparo dos profissionais para o atendimento das demandas provenientes das escolas e para o estabelecimento de parceria com os profissionais. Isto pode e deve ser facilitado pelo Programa de Saúde da Família (PSF).

\section{Saúde Ocular e tracoma}

Para o desenvolvimento desse tema solicitado pelos professores, houve a colaboração de uma médica sanitarista da Secretaria da Saúde do Município, que introduziu noções básicas sobre Saúde Ocular, capacitando, também, os professores para a realização do Teste de Snellen, riscos de acidente ocular e busca ativa do tracoma.

O tracoma é uma moléstia infecciosa de alta contagiosidade e, por esse motivo, quando, em 1995, surgiu nas crianças das escolas daquele Município, houve necessidade de estabelecer parcerias para sua resolução, entre órgãos de saúde municipais e estaduais e a Secretaria da Educação.

Os professores, que já faziam parte da Secretaria da Educação da Cidade, foram então capacitados pela Secretaria da Saúde do Município de São Paulo e adquiriram noções básicas sobre a doença e seus riscos; porém, os que foram admitidos posteriormente não conheciam a doença e mostravam-se ansiosos em obter esses conhecimentos.

Como recurso didático foram utilizadas as técnicas de discussão em grupo e um álbum seriado com gravuras e textos. Após a capacitação teórica, todos os professores participaram de um treinamento prático, realizando o Teste de Snellen uns nos outros, a fim de possibilitar a memorização da técnica aprendida. Foi ainda ensinada a técnica de detecção de casos de tracoma para o encaminhamento ao oftalmologista.

\section{Saúde Auditiva}

A Prevenção de Deficiência Auditiva foi também um dos objetivos de capacitação dos professores. Os promotores da saúde devem estar aptos e adquirir conhecimentos por meio de informações específicas sobre a anatomia e fisiologia auditiva, para detectar os sinais e sintomas da deficiência auditiva e prevenir os riscos de acidentes auditivos que, na infância, geralmente ocorrem após a introdução de objetos e líquidos das mais diversas naturezas nos ouvidos.

A audição é um dos sentidos que possibilita ao ser humano a convivência em todos os âmbitos da sociedade a que pertence. A criança portadora de deficiência auditiva, geralmente, tem maior dificuldade no aprendizado e no desenvolvimento cognitivo. Desta forma, a observação sistematizada dos alunos pelo professor capacitado pode prevenir ou minimizar os agravos que propiciem a surdez infantil que, se ocorrer, poderão causar danos irreversíveis para a vida.

Para a capacitação em Saúde Auditiva, contou-se com a colaboração de uma fonoaudióloga da Secretaria da Saúde do Município que realizou uma Oficina com os professores desenvolvendo os temas: fisiologia da fala e da audição, distúrbios da fala, proteção das cordas vocais e detecção precoce dos distúrbios 
auditivos.

\section{Verminose}

As verminoses são doenças parasitárias resultantes da poluição do ambiente, da água e do solo. Na maioria das vezes, os parasitas são transmitidos pela água por eles contaminada, por alimentos contaminados ou pelas pessoas com hábitos inadequados de higiene ${ }^{11}$.

Muito embora as doenças parasitárias não tenham características que facilitem sua propagação como ocorre com as moléstias infecto-contagiosas, elas ocupam um lugar de destaque entre as doenças da infância.

As formas de infestação mais comuns são por parasitas como os protozoários (toxoplasmose, amebíase e giardíase, entre outros) e por helmintos (ascaridíase, teníase, cisticercose, entre outras); assim, a prevenção das doenças pela adequação das condições de saneamento básico, a adoção de formas adequadas de higiene pessoal e a manipulação de alimentos foram amplamente discutidas com os professores, de modo que pudessem trabalhar esses temas com seus alunos.

Como estratégia, dividiram-se os temas por grupos formados pelos professores. Propôs-se, então, que depois de um levantamento bibliográfico, cada grupo apresentasse o seu tema para os outros grupos e como fonte para pesquisas foram oferecidos textos, apostilas e prospectos de campanhas. Foram confeccionados pelos educadores alguns cartazes para a exposição do tema.

\section{Doenças Infecciosas e Vacinação}

É importante salientar que a grande maioria das doenças imunoprevinívies tais como o sarampo, a tuberculose, a hepatite e o tétano são mortais para as crianças; porém, quando estas estão vacinadas, esse risco diminui aproximando-se da inexistência ${ }^{12}$.

O incentivo à vacinação no Brasil já é comum há anos; entretanto, as escolas quase não têm participado desse processo. Quando os alunos são matriculados na escola, geralmente, eles têm em média sete anos, idade em que a vacinação, preconizada pelo Ministério da Saúde, já deveria estar concluída. Nem sempre isso tem acontecido, então, se os professores estiverem habilitados para a verificação das carteiras de vacinação poderão reconhecer as vacinas que estão faltando e encaminhá-los às Unidades Básicas de Saúde para que recebam a dose ou doses faltantes. Ou, ainda, nos municípios que já implantaram o PSF, podem contar com a parceria dos agentes comunitários de saúde, que tem como uma de suas prioridades verificar e acompanhar o estado vacinal de cada criança de sua área de atuação.

Visando o desenvolvimento de uma ação mais abrangente, optou-se por começar visitas às escolas de forma a discutir e envolver todos os professores das escolas-pólo. Como resultado, foi feito um mutirão de verificação das carteiras de vacinação das crianças e quando necessário, foram encaminhados à Unidade Básica de Saúde*.

\section{Prevenção de Acidentes na Escola}

Os acidentes também são preveníveis, assim, a observação e detecção dos principais fatores de riscos de acidentes no ambiente físico e social da escola e em seu entorno possibilitam o planejamento para a educação em saúde e a adoção de medidas que minimizem ou eliminem tais riscos.

Para desenvolver habilidades que permitam o ajustamento às novas situações diárias e

Durante o período de desenvolvimento deste estudo no Município de Vargem Grande Paulista ainda não havia sido implantado o Programa de Saúde da Família. 
impeçam situações de riscos para a saúde é preciso adotar práticas de segurança; desenvolver destrezas e formar atitudes favoráveis à prevenção de acidentes, tais como: atenção, observação, advertência, cautela, consideração pela segurança dos outros, respeito por regras, paciência e interesse em comportar-se com segurança.

Baseando-se nesses conceitos, o tema "Prevenção de Acidentes na Escola" foi incluído no processo de educação continuada dos professores.

A observação sistematizada e a sinalização dos fatores de riscos também foram estimuladas como um dos meios para a resolução ou minimização de acidentes nas escolas.

Intercorrências Mais Comuns na Escola e Primeiros Socorros

Como consequiência das discussões sobre riscos de acidentes na escola, os professores foram capacitados para realizar os primeiros socorros, entendidos como a ação de socorrer a todas e quaisquer intercorrências que venham a acontecer com os alunos, desde a atenção às pequenas escoriações e impactos até fraturas de membros que necessitem de encaminhamento imediato para uma Unidade de Pronto Atendimento.

O objetivo principal desta discussão foi proporcionar aos professores a oportunidade de esclarecer dúvidas, propiciar maior segurança, eliminar conceitos errôneos, impedir o uso inadequado de medicações e outras substâncias no cuidado aos ferimentos e também nas manifestações de crises convulsivas, que costumam assustar muito as pessoas despreparadas para prestar o devido socorro.

A experiência foi bastante positiva; os professores participantes, aproximadamente 95 , mostraram-se muito interessados, tendo referido a insegurança que sentiam antes da capacitação por falta de conhecimento e preparo, quando tinham necessidade de prestar socorro a qualquer criança ferida.
Foram fornecidos textos complementares de apoio para cada uma das escolas sobre vários temas, entre os quais Prevenção de Acidentes na Escola e Recomendações para o Atendimento de Primeiros Socorros, onde foi sugerida a padronização da Caixa de Primeiros Socorros, adotada em seguida por todas as Escolas da Rede Municipal de Ensino da Cidade de Vargem Grande Paulista, conforme descrito abaixo.

Sugestão para Composição da Caixa de Primeiros Socorros para as Escolas:

$\begin{array}{ll}\checkmark & 1 \text { tala } \\ \checkmark & 1 \text { tesoura } \\ \checkmark & 1 \text { rolo de algodão } \\ \checkmark & 1 \text { termômetro } \\ \checkmark & 3 \text { rolos de ataduras de crepe média } \\ \checkmark & 1 \text { rolo de fita crepe } \\ \checkmark & 1 \text { rolo de esparadrapo } \\ \checkmark & 5 \text { Pacotes com 10 gases cada } \\ \checkmark & 1 \text { frasco de } 250 \text { ml de soro fisiológico } \\ \checkmark & 1 \text { Par de luvas de procedimento } \\ \text { descartável } \\ \checkmark & 1 \text { pedra de sabão de coco (dividida em } \\ \text { pedaços pequenos - para o uso descartável) }\end{array}$

\section{Alimentação, Subnutrição e Anemia}

A Educação em Saúde procurou abranger a educação alimentar com o objetivo de corrigir hábitos inadequados de alimentação. Essa difícil tarefa exige ação dos pais, professores, nutricionistas e merendeiras, para que, num esforço conjunto, desde cedo as crianças adquiram hábitos saudáveis de alimentação, prevenindo a subnutrição ou até mesmo a desnutrição crônica que têm afetado grande número de crianças no país. O erro alimentar também tem sido uma das causas da obesidade infantil, tão freqüente na atualidade.

Para esse tema, os professores contaram com a presença das merendeiras das es- 
colas e de uma médica da Secretaria de Saúde do Município, especialista em nutrição e alimentação alternativa. Como parte da atividade prática do dia, o grupo participante, formado por educadores e por merendeiras, preparou sob orientação, um almoço comunitário utilizando alimentos ricos em vitaminas e proteínas.

Todos os temas acima descritos foram parte de uma discussão abrangente na qual os professores puderam participar de "jogos educativos" e técnicas de trabalho em grupo que possibilitaram melhorar seu autoconhecimento e sua auto-estima. Sensibilizaram-se para a importância da parceria com os pais para a melhoria do desempenho das atividades de ensino e para a importância da comunicação dialógica para o relacionamento humano, incluindo reflexões sobre a necessidade do respeito mútuo, de valorizar o multiculturalismo, a liberdade e a democracia.

\section{RESULTADOS}

Em todo o processo, houve a preocupação de usar uma metodologia participativa na qual as situações de ensino-aprendizagem dos professores eram criadas conjuntamente, tanto no que se refere à teoria como à prática. As discussões partiam do conhecimento e das experiências que cada um trazia da sua prática pedagógica, assim como as novas ações eram discutidas e propostas para serem realizadas no seu próprio local de atuação, isto é, junto aos alunos que estavam sob sua responsabilidade.

Nos trabalhos em grupo, num primeiro momento, não havia a participação efetiva de todos os professores. Alguns, talvez por características de personalidade se destacavam mais, porém não davam oportunidade para os outros se expressarem. Aos poucos, as pessoas passaram a respeitar mais a visão do outro, mesmo que diferente da sua, ao mesmo tempo que ocorria uma maior participação daqueles professores que nem sempre se posicionavam frente às discussões.

Alguns professores manifestavam constantemente a satisfação em participar do processo, sentiam-se privilegiados e, ao mesmo tempo que se apropriavam de novos conceitos, sentiam-se mais responsáveis em dividir com os outros suas novas conquistas. Percebia-se claramente que esse sentimento estava relacionado com o conhecimento que tinham em relação à formação deficitária de parte do grupo participante; desta maneira, sentiam necessidade de compartilhar com seus companheiros aquilo que estavam aprendendo.

É preciso esclarecer que a participação de professores no processo de capacitação não foi restrita aos 20 que fizeram parte do universo da pesquisa; desta forma, em muitos momentos deste processo, houve a participação de aproximadamente 90 professores que lecionavam no Ensino Infantil e Fundamental do Município.

O trabalho com os professores durou 30 meses; assim, pôde-se acompanhar um crescimento gradativo do conhecimento sobre a realidade na qual eles estavam inseridos. A consciência dos participantes, antes ingênua, passou a uma consciência crítica a partir de uma educação participativa e, nos termos de Frei$\mathrm{re}^{13}$ (p.61), "dialogal e ativa, voltada para a responsabilidade social e política, caracterizada pela profundidade na interpretação dos problemas".

Também como parte dos resultados do processo de Educação Continuada realizado com os professores de Vargem Grande Paulista, pode-se destacar, além do crescimento cognitivo alcançado, a aquisição de algumas habilidades tais como:

a) Coordenação e realização pelos educadores capacitados do 1을 Seminário de Educação em Saúde e Ambiental, com a participação de todos os professores da Rede Municipal de 


\section{Ensino;}

b) Organização do 1ำ Fórum de Educação em Saúde e Ambiental de Vargem Grande Paulista;

c) Preparo para desenvolver ações preventivas e de promoção da saúde na comunidade escolar;

d) Preparo para identificar os problemas de saúde das crianças, a partir da observação contínua que possibilitou a percepção de mudanças, às vezes sutis (sinais) ligadas ao aparecimento de estado patológico (sintomas);

e) Preparo para encaminhar corretamente para os recursos disponíveis os casos identificados.

Os professores perceberam também a importância de seu papel como educadores para a promoção da saúde na escola e na construção da Escola Promotora da Saúde, e a Educação Continuada como um processo profissional extremamente importante e capaz de provocar profundas mudanças no processo de ensino-aprendizagem. Alguns professores afastados há muitos anos optaram por retomar seus estudos e passaram a cursar a universidade, e outros seguiram com trabalhos voltados para a comunidade utilizando a metodologia aprendida durante o processo de Educação Continuada.

\section{CONSIDERAÇÕES FINAIS}

A Educação em Saúde no Brasil já percorreu um longo processo determinado pelos diferentes paradigmas de saúde e de doença vigentes em cada época, em cada fase da história. Começou pela concepção higienista que propunha medidas de limpeza e asseio (higienicismo) dos escolares, com a finalidade de evitar doenças contagiosas e comportamentos sociais indesejáveis. Posteriormente surgiu a fase biologicista na qual supunha-se que o baixo rendimento escolar do aluno estivesse intimamente, se não exclusivamente, relacionado a um estado de doença ligado ao estado nutricional ou à capacidade mental do indivíduo, surgindo então os "diagnósticos patológicos", atribuídos aos "distúrbios de aprendizagem" e à "disfunção cerebral", que resultaram na proliferação de especialistas da área da saúde como agentes "convocados" para fornecer explicações sobre o fenômeno do insucesso e da evasão escolar.

Atualmente, vive-se o "novo" conceito no qual deve-se enfatizar a qualidade de vida para a obtenção e conservação da saúde. A Promoção e a Educação em saúde na escola devem partir deste pressuposto. Assim sendo, uma Escola Promotora da Saúde deve "procurar constantemente fortalecer a sua condição de se constituir e representar um ambiente saudável para se viver, ensinar e trabalhar"14.

A Educação em Saúde vista sob esse paradigma deve proporcionar aos partícipes a oportunidade de atuarem como agentes de transformação da realidade do meio em que vivem, para que estejam aptos para lutar e obter melhores condições de vida com saúde e qualidade. Assim sendo, fica claro que a Promoção e Educação em Saúde não podem mais ficar restritas aos limites do setor saúde e ser responsabilidade exclusiva do profissional da saúde; é preciso estabelecer parcerias e preparar profissionais da educação para que, eles também, exerçam o papel de Promotores da Saúde, dentro da escola e na comunidade em que vivem.

Finalmente, pode-se afirmar que a Educação e a Promoção da Saúde foram incorporadas no cotidiano dos professores de Vargem Grande Paulista que participaram da Educação Continuada e que, mesmo após o término do processo, continuaram a realizar o processo pedagógico de forma integrada, utilizando estes conceitos transversalmente no currículo dos escolares visando sempre à melhoria da qualidade de vida dos alunos e de todos que convivem na escola. 


\begin{abstract}
This project, developed during thirty months in Vargem Grande Paulista, state of São Paulo, had the objective of training Primary and Secondary School teachers to develop the Health Education process, together with their students. A questionnaire was used with open and closed questions and a focus group technique, with results being analyzed quali-quantitatively. It began with a situational diagnosis producing "generative themes": Health Promotion School, Observation of School-aged Children, Accident Prevention, among others. These enabled the discussion on health in an integral way and the establishment of the latter's relationship to the environment. The second stage consisted of process evaluation. As a result, the training, carried out based on the idea of health as synonymous with quality of life, provided teachers with the possibility of reviewing their concepts of health and health education, as well as their role as agents of health promotion and illness prevention. It was also seen that they became trained to develop the studied themes in a transversal way.
\end{abstract}

Key words: Health Education. Health Promotion. Health Promotion School. Continued Education.

\section{REFERENCIAS}

1. Iervolino SA. Escola Promotora da Saúde: um projeto de qualidade de Vida. [Dissertação]. São Paulo (SP): Faculdade de Saúde Pública/USP; 2000. p.33-7

2. Ministério da Saúde (BR). Promoção da Saúde: Carta de Ottawa. Brasília (DF): Ministério da Saúde; 1996. p.19.

3. Gadotti M. Convite á Leitura de Paulo Freire. $2^{\mathrm{a}}$ ed. São Paulo (SP): Scipione; 1991. p.136.

4. OPAS. Oficina Sanitária Panamericana. Escuelas promotoras de salud: modelo y guía para la acción. Washington (DC); 1996. p.1-19.

5. Martins Junior. T. Apoderamento. SANARE, Revista de Políticas Públicas 2003 Fev/Mar; IV(1):27-9.

6. Pelicioni MCF. Educação em Saúde e educação Ambiental: estratégias de construção da escola promotora da saúde. [Livre-Docência]. São Paulo (SP): Faculdade de Saúde Pública/USP; 2000. p. 253.

7. World Health Organization. WHOLIS. Health promotion and healthy lifestyles. Geneva;
January 2004. 2 p. Avaiable from: URL: http:// bases.bireme.br/cgi-bin/wxislind.exe/iah/online

8. Freire $\mathrm{P}(\mathrm{a})$. Educação e mudança. Rio de Janeiro (RJ): Paz e Terra; 1983.

9. Iervolino SA, Pelicioni MCF. A utilização do grupo focal como metodologia na promoção da saúde. Revista da Escola de Enfermagem da USP 2004; 2 (35): 115-21.

10. Cianciarullo TI. Instrumentos básicos para o cuidar: um desafio para a qualidade de assistência. São Paulo (SP): Atheneu; 1996.

11. Marcondes RS, coordenadora. Saúde na escola: 1 o grau: livro do professor. São Paulo(RJ): IBRASA; 1979.

12. Farhat C. Fundamentos e Práticas das imunizações em clínica médica e pediatria. $3 a$ ed. Rio de Janeiro (RJ) / São Paulo (SP): Livraria Atheneu; 1989.

13. Freire $\mathrm{P}(\mathrm{b})$. Educação como prática da liberdade. 14 ed. Rio de Janeiro(RJ): Paz e Terra; 1983.

14. Organización Panamericana de la Salud. Escuelas promotoras de la salud: entornos saludables y mejor salud para las geraciones futuras. Washington (DC): OPAS - Comunicación para la Salud(13); 1998. 


\section{Anexo 1 - Ficha de Observação das Condições de Saúde do Aluno}

A ficha de observação das condições de saúde do aluno visa facilitar o registro das observações de saúde e doença dos alunos, pelo professor. A importância do registro se dá à medida que o professor pode ter um histórico das condições gerais do aluno, facilitando nas resoluções dos problemas. Quando se sente apto o professor faz as orientações específicas quando não, deve fazer o encaminhamento aos profissionais competentes sempre munido dos dados observados e registrados nesta ficha.

NOME:

IDADE:

CLASSE:

PROFESSOR:

Histórico de Saúde

1- Estado Vacinal

2- Portador de deficiência física ou mental?
a) ( ) completo
a) ( ) não
b) ( ) incompleto.
b) ( ) $\operatorname{sim}$.
c) Qual está faltando?
c) Qual?

3- Portador de Doenças Crônicas
a) ( ) não
b)( ) sim.c)

Qual(ais)?
c.1)( ) diabetes
c.2)( ) epilepsia
c.4)( ) problemas urinários
c.3)( ) asma/bronquite
c.5) ( ) cardíaco
c.6)( ) Outros. Quais?

Registro das observações efetuadas (breve descrição).Assinar e datar.

(verso da folha)

FICHA DE SAÚDE DOS ESCOLARES
OBSERVAÇAO DE SAÚDE DO ESCOLAR

Observar:

Características Físicas; Características

Mentais e Sociais; Imunização $\underline{\text { O Escolar apresentando Desvios da Normali- }}$ dade

Observar: Estado Geral; ajustamento psicossocial; Postura e Marcha; Cabelos e Couro Cabeludo; Pele; Olhos/ visão; Nariz/ olfato; Boca, Dentes e Garganta/ Fala; Ouvidos/audição; Pescoço; Tronco; Membros superiores; Membros inferiores

Mês: Problema detectado/ Resolução/ Classe/ Professor/ Data 